\title{
Hyperhistory and the Philosophy of Information Policies
}

\author{
Luciano Floridi
}

\section{Hyperhistory}

More people are alive today than ever before in the evolution of humanity. And more of us live longer and better today than ever before. To a large measure, we owe this to our technologies, at least insofar as we develop and use them intelligently, peacefully, and sustainably.

Sometimes, we may forget how much we owe to flints and wheels, to sparks and ploughs, to engines and satellites. We are reminded of such deep technological debt when we divide human life into prehistory and history. That significant threshold is there to acknowledge that it was the invention and development of information and communication technologies (ICTs) that made all the difference between who we were and who we are. It is only when the lessons learnt by past generations began to evolve in a Lamarckian rather than a Darwinian way that humanity entered into history.

History has lasted 6,000 years, since it began with the invention of writing in the fourth millennium BC. During this relatively short time, ICTs have provided the recording and transmitting infrastructure that made the escalation of other technologies possible, with the direct consequence of furthering our dependence on more and more layers of technologies. ICTs became mature in the few centuries between Guttenberg and Turing. Today, we are experiencing a radical transformation in our ICTs that could prove equally significant, for we have started drawing a new threshold between history and a new age, which may be aptly called hyperhistory (Fig. 1). Let me explain.

Prehistory and history work like adverbs: they tell us how people live, not when or where. From this perspective, human societies currently stretch across three ages, as ways of living. According to reports about an unspecified number of uncontacted tribes in the Amazonian region (http://www.survivalinternational.org/), there are

\footnotetext{
L. Floridi $(\bowtie)$

Oxford Internet Institute, University of Oxford, 1 St Giles, OX1 3JS Oxford, UK

e-mail: luciano.floridi@oii.ox.ac.uk
} 


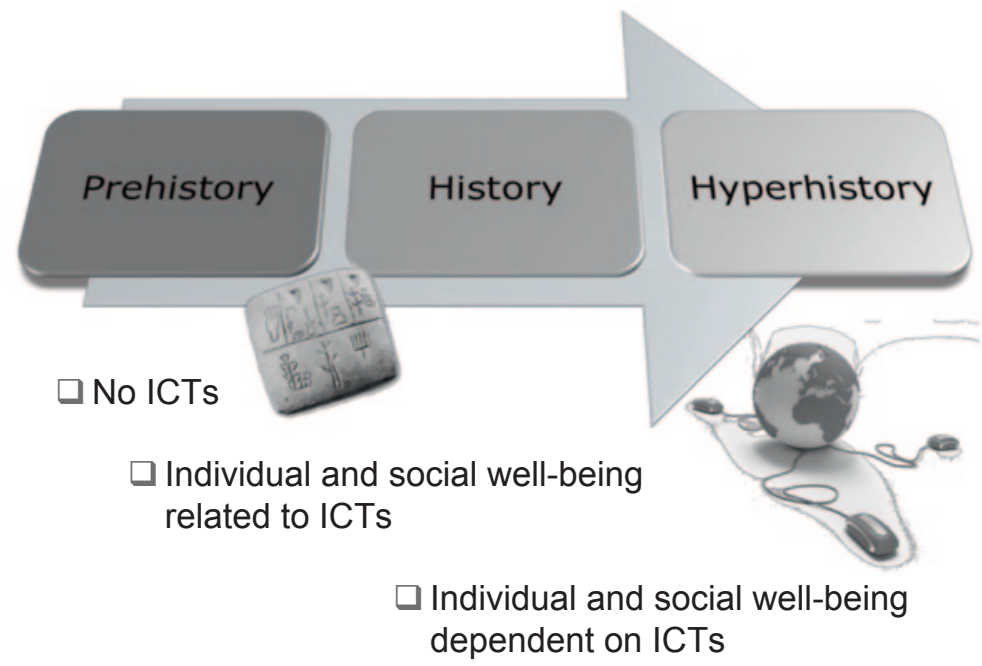

Fig. 1 From prehistory to hyperhistory

still some societies that may be living prehistorically, without recorded documents. If one day such tribes disappear, the end of the first chapter of our evolutionary book will have been written. The greatest majority of people today still live historically, in societies that rely on ICTs to record and transmit data of all kinds. In such historical societies, ICTs have not yet overtaken other technologies, especially energy-related ones, in terms of their vital importance. Then there are some people around the world who are already living hyperhistorically, in societies or environments where ICTs and their data processing ${ }^{1}$ capabilities are the necessary condition for the maintenance and any further development of societal welfare, personal well-being, as well as overall flourishing. The nature of conflicts provides a sad test for the reliability of this tripartite interpretation of human evolution. Only a society that lives hyperhistorically can be vitally threatened informationally, by a cyber attack. Only those who live by the digit may die by the digit (Floridi and Taddeo forthcoming).

To summarise, human evolution may be visualised as a three-stage rocket: in prehistory, there are no ICTs; in history, there are ICTs, they record and transmit data, but human societies depend mainly on other kinds of technologies concerning primary resources and energy; in hyperhistory, there are ICTs, they record, transmit and, above all, process data, increasingly autonomously, and human societies become vitally dependent on them and on information as a fundamental resource. Added-value moves from being ICT-related to being ICT-dependent.

\footnotetext{
${ }^{1}$ This is the way I understand the reference in the Manifesto to a computational turn.
} 
If all this is even approximately correct, the emergence from its historical age represents one of the most significant steps taken by humanity for a very long time. It certainly opens up a vast horizon of opportunities as well as challenges, all essentially driven by the recording, transmitting, and processing powers of ICTs. From synthetic biochemistry to neuroscience, from the Internet of things to unmanned planetary explorations, from green technologies to new medical treatments, from social media to digital games, from agricultural to financial applications, from economic developments to the energy industry, our activities of discovery, invention, design, control, education, work, socialisation, entertainment, care and so forth would be not only unfeasible but unthinkable in a purely mechanical, historical context. They are all hyperhistorical in nature.

It follows that we are witnessing the outlining of a macroscopic scenario in which an exponential growth of new inventions, applications, and solutions in ICTs are quickly detaching future generations from ours. Of course, this is not to say that there is no continuity, both backward and forward. Backward, because it is often the case that the deeper a transformation is, the longer and more widely rooted its causes are. It is only because many different forces have been building the pressure for a very long time that radical changes may happen all of a sudden, perhaps unexpectedly. It is not the last snowflake that breaks the branch of the tree. In our case, it is certainly history that begets hyperhistory. There is no ASCII without the alphabet. Forward, because it is most plausible that historical societies will survive for a long time in the future, not unlike the Amazonian tribes mentioned above. Despite globalisation, human societies do not parade uniformly forward, in synchronic steps.

\section{The Philosophy of Information Policies}

Given the unprecedented novelties that the dawn of hyperhistory is causing, it is not surprising that many of our fundamental philosophical views, so entrenched in history and above all so modern (in the sense of this word explained in the Manifesto), may need to be upgraded, if not entirely replaced. Perhaps not yet in academia, think tanks, research centres, or R\&D offices, but clearly in the streets and online, there is an atmosphere of confused expectancy, of exciting, sometimes naïve, bottom-up changes in our views about (i) the world, (ii) about ourselves, (iii) about our interactions with the world and (iv) among ourselves.

These four focus points are not the result of research programmes, nor of the impact of successful grant applications. Much more realistically and powerfully, but also more confusedly and tentatively, the changes in our Weltanschauung are the result of our daily adjustments, intellectually and behaviourally, to a reality that is fluidly changing in front of our eyes and under our feet, exponentially and relentlessly. In the Manifesto, I described this state in terms of "building the raft while swimming", hacking Neurath's famous analogy. We are finding our new balance by shaping and adapting to hyperhistorical conditions that have not yet sedimented 
into a mature age, and in which novelties are no longer disruptive but finally stable patterns of "more of approximately the same" (think, for example, of the car or the book industry, and the stability they have provided).

It is for this reason that the following terminology is only tentative and probably inadequate for capturing the intellectual novelty that we are facing. Our very conceptual vocabulary and our ways of making sense of the world (our semanticising processes and practices) need to be reconsidered and redesigned in order to provide us with a better grasp of our hyperhistorical age, and hence a better chance to shape it in the best way and deal with its challenges successfully. With this proviso in mind, it seems clear that a new philosophy of history, which tries to makes sense of our age as the end of history and the beginning of hyperhistory, invites the development of (see the fours points above) (i) a new philosophy of nature, (ii) a new philosophical anthropology, (iii) a synthetic e-nvironmentalism as a bridge between us and the world, and (iv) a new philosophy of politics among us.

In other contexts, I have argued that such an invitation amounts to a request for a new philosophy of information that can work at 360 degrees on our hyperhistorical condition (Floridi 2011). I have sought to develop a philosophy of nature in terms of a philosophy of the infosphere (Floridi 2003), and a philosophical anthropology in terms of a fourth revolution in our self-understanding-after the Copernican, the Darwinian, and Freudian ones - that re-interprets humans as informational organisms living and interacting with other informational agents in the infosphere (Floridi 2008, 2010). Finally, I have suggested that an expansion of environmental ethics to all environments - including those that are artificial, digital or synthetic should be based on an information ethics for the whole infosphere (Floridi forthcoming). What I have not done is to outline a philosophy of politics consistent with such initial steps. The following remarks represent the beginning of this new effort.

\section{Political Apoptosis: from the Historical State to the Hyperhistorical MASs}

The long-term perspective, introduced in the previous section, should help to explain the process of political apoptosis ${ }^{2}$ that we are undergoing, to borrow a concept from cell biology: the State developed by becoming more and more an Information Society, but in so doing it increasingly made itself less and less the main information agent, because what made the State possible and then predominant,

\footnotetext{
${ }^{2}$ Apoptosis (also known as programmed cell death) is a natural and normal form of self-destruction in which a programmed sequence of events leads to the elimination of cells. Apoptosis plays a crucial role in developing and maintaining the health of the body by eliminating cells once they become old, unnecessary, or unhealthy. I am indebted to Judith Simon for having warned me against the dangerous overtones in the concept, with its potential connection to Nazi views about biological purity and purification. Of course this is not the way the concept should be understood here, I have just been unable to find a better way of expressing the idea so far.
} 


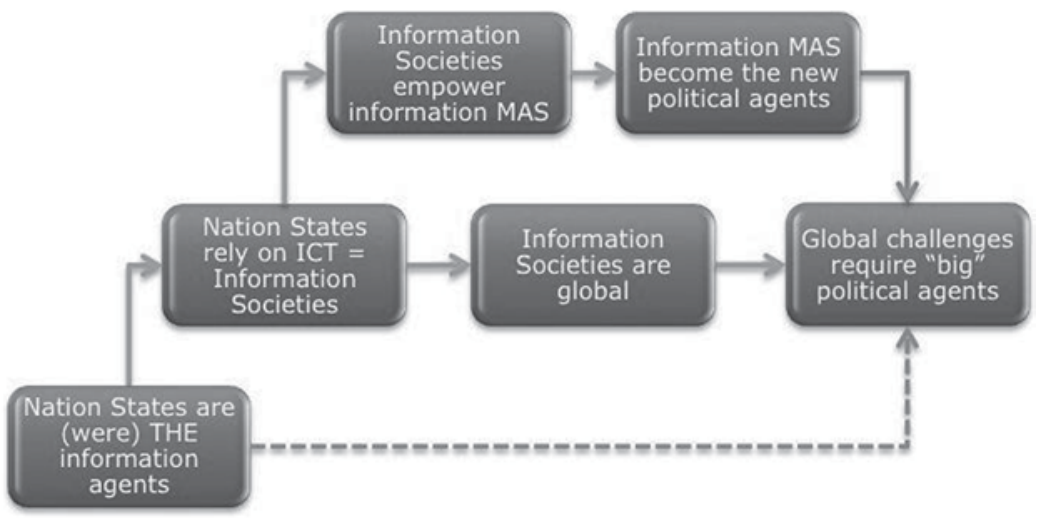

Fig. 2 From the State to the MASs

as a historical driving force in human politics, namely ICTs, is also what is now making it less central hyperhistorically, in the social, political and economic life of humanity across the world (Fig. 2). Three related reasons are worth highlighting by way of explanation.

1. Power: ICTs "democratise" data and the processing/controlling power over them, in the sense that both now tend to reside and multiply in a multitude of repositories and sources, thus creating and empowering a potentially boundless number of non-state agents, from the single individual to associations and groups, from macro-agents, like multinationals, to international, intergovernmental as well as nongovernmental, organisations. The State is no longer the only, and sometimes not even the main, agent in the political arena that can exercise informational power over other informational agents, in particular over (groups of) human informational organisms. The European Commission, for example, recognised the importance of such new agents in the Cotonou Agree$m e n t^{3}$ between the European Union (EU) and the Africa, Caribbean and Pacific (ACP) countries, by acknowledging the important role exercised by a wide range of nongovernmental development actors, and formally recognising their participation in ACP-EU development cooperation. According to Art. 6 of the Cotonou Agreement, such non-state actors comprise: "the private sector; economic and social partners, including trade union organisations; civil society in all its forms, according to national characteristics". ${ }^{4}$ The phenomenon is generating a new tension between power and force, where power is informational and exercised through the elaboration and dissemination of norms, whereas force is physical

\footnotetext{
${ }^{3}$ See Second Revision of the Cotonou Agreement, Agreed Consolidated Text, 11 March 2010. http:// ec.europa.eu/development/icenter/repository/second_revision_cotonou_agreement_20100311. pdf.

${ }^{4}$ I am grateful to Mireille Hildebrandt for calling my attention to this document.
} 
and exercised when power fails to orient the behaviour of the relevant agents and norms need to be enforced.

2. Space: ICTs de-territorialise human experience. They have made regional borders porous or in some cases entirely irrelevant. They have also created, and are exponentially expanding, regions of the infosphere where an increasing number of agents (not only people, see above) operate and spend more and more time. Such regions are intrinsically stateless. This is generating a new tension between geo-politics, which is global and non-territorial, and the Nation State, which still defines its identity and political legitimacy in terms of a sovereign territorial unit, as a Country.

3. Organisation: ICTs fluidify the topology of politics. ICTs do not merely enable but actually promote the agile, temporary and timely aggregation, disaggregation and re-aggregation of distributed (Floridi forthcoming) groups around shared interests across old, rigid boundaries, represented by social classes, political parties, ethnicity, language barriers, and so forth. This is generating a new tensions between the Nation State, still understood as a major organisational institution, yet no longer monolithic but increasingly morphing into a multiagent system itself (see below), and a variety of equally powerful, indeed sometimes even more politically influential (with respect to the old Nation State) and powerful (see above), non-State organisations. The debate on direct democracy is thus reshaped. We used to think that it was about how the Nation State could re-organise itself internally, by designing rules and having the means to promote forms of democracy in which citizens could vote on policy initiatives directly almost in real time. We thought of it as a complementary alternative to forms of representative democracy. The reality is that direct democracy has become a medialed democracy, in which multiagent systems (understood as distributed groups temporary and timely aggregated around shared interests) have multiplied and become sources of influence external to the Nation State. Citizens vote for their representatives and influence them via opinion polls.

Because of 1-3, the unique position of the historical State as the information agent is being undermined from below and overridden from above by the emergence of multiagent systems or MASs, which have the data, the power (and sometimes even the force, as in the case of cyber threats), the space, and the organisational flexibility to erode its political clout, steal its authority and, in the long run, make it redundant in contexts where it was once the only or the predominant informational agent. The recent Greek crisis and the actual agents involved in its management offer a good template: the Greek Government and the Greek State had to interact "above" with the EU, the European Central Bank, the IMF, the rating agencies, and so forth, and "below" with the Greek mass media and the people in Syntagma square, the financial markets and international investors, German public opinion, and so forth.

A much more networked idea of political interactions makes possible a degree of tolerance towards, and indeed feasibility of, localisms, separatisms, as well as movements and parties favouring autonomy or independence that would have been inconceivable in Modern times. From Padania (Italy) to Catalonia (Spain), from Scotland (Great Britain) to Bavaria (Germany), one is reminded that almost 
in any European country, for example, hyperhistorical trends may resemble preWestphalian equilibria. ${ }^{5}$

Of course, the historical State is not giving up its role without a fight. In many contexts, it is trying to reclaim its primacy as the information super-agent governing the political life of the society that it organises. In some cases, the attempt is blatant: Labour Government's failed plan to introduce compulsory ID in the $\mathrm{UK}^{6}$ should be read from this perspective. In many cases, it is "historical resistance" by stealth, as when an information society - defined by the essential role played by intellectual, intangible assets (knowledge-based economy), information-intensive services (business and property services, finance and insurance), and public sectors (especially education, public administration and health care) - is largely run by the State, which simply maintains its role of major informational agent no longer just legally, on the basis of its power over legislation and its implementation, but now also economically, on the basis of its power over the majority of information-based jobs. The intrusive presence of so-called State Capitalism with its SOE (State Owned Enterprises) all over the world and especially in China is an obvious symptom.

Similar forms of resistance seem only able to delay the inevitable rise of political MASs. Unfortunately, they may involve huge risks, not only locally, but also globally. Paradoxically, while humanity is moving into a hyperhistorical age, the world is witnessing the rise of China, currently a most "historical" Sovereign State, and the decline of the US, a Sovereign State that more than any other superpower in the past already had a hyperhistorical vocation in its federal organisation. This is risky, because the anachronistic historicism of some of China's policies and humanity's growing hyperhistoricism are heading towards a confrontation. It may not be a conflict, but hyperhistory is a force whose time has come, and while it seems very likely that it will be the Chinese State that will emerge deeply transformed, one can only hope that the inevitable friction will be as painless and peaceful as possible. The previous conclusion holds true for the historical State in general: in the future, we shall see the political MASs acquire increasing prominence, with the State itself progressively abandoning its resistance to hyperhistorical changes and evolving into a MAS itself. Good examples are provided by devolution or the growing trend in making central banks, like the Bank of England or the European Central Bank, independent, public organisations.

\section{The Nature and Problems of the Political MAS}

The time has come to consider the nature of the political MAS more closely and some of the questions that its emergence is already posing.

\footnotetext{
${ }^{5}$ The entry on "List of active separatist movements in Europe" in Wikipedia is both informative and eye opening. http://en.wikipedia.org/wiki/List_of_active_separatist_movements_in_Europe.

${ }^{6}$ The Labour Government introduced the first Identity Cards Bill in November 2004, after several intermediary stages, the Identity Cards Act was finally repealed by the Identity Documents Act 2010 on 21 January 2011.
} 
The political MAS is a system constituted by other systems, which, as a single agent (Floridi and Sanders 2004), is

a. teleological, the MAS has a purpose, or goal, which it pursues through its actions;

b. interactive, the MAS and its environment can act upon each other;

c. autonomous, the MAS can change its states without direct response to interaction: it can perform internal transitions to change its states. This imbues the MAS with some degree of complexity and independence from its environment; and finally

d. adaptable, the MAS' interactions can change the rules by which the MAS changes its states. Adaptability ensures that the MAS learns its own mode of operation in a way that depends critically on its experience.

The political MAS is thus an intelligent ${ }^{7}$ MAS when it implements features a-d efficiently and effectively, minimising resources, wastefulness and errors while maximising the returns of its actions.

The emergence of intelligent, political MASs poses many serious questions, which can only be quickly reviewed here.

\subsection{Identity and Cohesion}

Throughout history, the State has dealt with the problem of establishing and maintaining its own identity by working on the equation between State=Nation, often through the legal means of Citizenship and the narrative rhetoric of Space (the Mother/Father Land) and Time (Story in the sense of traditions, recurrent celebrations of past Nation-building events, etc.). Consider, for example, the invention of mandatory military service during the French Revolution, its increasing popularity in modern history, but then the decreasing number of Sovereign States that still impose it nowadays. It is a sign of anachronism that, in moments of crisis, Sovereign States still give in to the temptation of fuelling nationalism. The equation between State, Nation, Citizenship and Land/Story had the further advantage of providing an answer to a second problem, that of cohesion, for it answered not just the question of who or what the State is, but also the question of who or what belongs to the State and hence may be subject to its norms and actions.

New political MAS cannot rely on the same solution. Indeed, they face the further problem of having to deal with the decoupling of their political identity and cohesion. The political identity of a MAS may be very strong and yet unrelated to its temporary and rather loose cohesion, as it is the case with the Tea Party movement in the US. Both the identity and cohesion of a political MAS may be rather weak, as in the international Occupy movement. Or one may recognise a strong cohesion and yet an unclear or weak political identity, as with the population of tweeting individuals and their role during the Arab Spring. Both identity and cohesion of

\footnotetext{
${ }^{7}$ I am using the word 'intelligent' here is the same sense in which we find it in Artificial Intelligence, that is, as an equivalent to 'smart', when used in 'smart technologies'.
} 
a political MAS are established and maintained through information sharing. The Land is virtualised into the region of the infosphere in which the MAS operates. So Memory (retrievable recordings) and Coherence (reliable updates) of the information flow enable a political MAS to claim some identity and some cohesion, and therefore offer a sense of belonging. But it is, above all, the fact that the boundaries between the online and offline are disappearing, the appearance of the onlife experience, and hence the fact that the virtual infosphere can affect politically the physical space, that reinforces the sense of the political MAS as a real agent. If Anonymous had only a virtual existence, its identity and cohesion would be much less strong. Deeds provide a vital counterpart to the virtual information flow to guarantee cohesion. An ontology of interactions replaces an ontology of things (Floridi 2007).

\subsection{Consent}

A significant consequence of the breaking up of the equation political MAS $=\mathrm{Na}$ tion State $=$ Citizenship $=$ Land $=$ Story and of the decoupling of identity and cohesion in a political MAS is that the age-old theoretical problem of how consent to be governed by a political authority arises is being turned on its head. In the historical framework of social contract theory, the presumed default position is that of a legal opt-out: there is some kind (to be specified) of a priori, original consent, allegedly given by any individual subject to the political State, to be governed by the latter and its laws. The problem is to understand how such consent is given and what happens when the agent opts out of it (the out-law). In the hyperhistorical framework, the expected default position is that of a social opt-in, which is exercised whenever the agent subjects itself to the political MAS conditionally, for a specific purpose. Gathering consent around specific political issues becomes a continuous process. The problem is to understand what may motivate or indeed force agents (again, not just individual human beings, but all kinds of agents) to give such consent and become engaged, and what happens when such agents, unengaged by default (note, not disengaged, for disengagement presupposes a previous state of engagement) prefer to stay away from the activities of the political MAS. Failing to grasp the previous transformation from historical opt-out to hyperhistorical opt-in means being less likely to understand the apparent inconsistency between the disenchantment of individuals with politics and the popularity of global movements, international mobilisations, activism, voluntarism, and other social forces with huge political implications. What is moribund is not politics tout court, but historical politics, that based on Parties, Classes, fixed Social Roles, and the State, which asked political legitimacy only once and spent it until revoked. The inching towards the so-called centre by parties in Liberal Democracies around the world and the "Get out the vote" strategies (GOTV a term used to describe the mobilisation of voters to ensure that those who can do vote) are evidence that engagement needs constantly renewed and expanded in order to win an election. Party (as well as Union) membership is a Modern feature that is likely to become increasingly less common. 


\subsection{Social vs. Political Space}

Understanding the previous inversion of default positions means being faced by a further problem. Oversimplifying, in prehistory, the social and the political spaces overlap because, in a stateless society, there is no real difference between social and political relations and hence interactions. In history, the State seeks to maintain such co-extensiveness by occupying all the social space politically, thus establishing the primacy of the political over the social. We have seen above that this may be based on normative or economic strategies, through the exercise of power, force, control, and rule-making. In hyperhistory, the social space is the original, default space from which agents may move to (consent to) join the political space. It is not accidental that concepts such as civil society, public sphere (also in a non-Habermasian sense) and community become increasingly important the more we move into a hyperhistorical context. The problem is to understand such social space where agents of various kinds are supposed to be interacting and give rise to the political MAS.

Each agent, as described in Sect. 4, has some degrees of freedom. By this I do not mean liberty, autonomy or self-determination, but rather, in the robotic sense, some capacities or abilities, supported by the relevant resources, to engage in specific actions for a specific purpose. To use an elementary example, a coffee machine has one degree of freedom: it can make coffee, once the right ingredients and energy are supplied. The sum of these agent's degrees of freedom are its "agency". When the agent is alone, there is of course only agency, no social let alone political space. Imagine Robinson Crusoe on his "Island of Despair". However, as soon as there is another agent (Friday on the "Island of Despair"), or indeed a group of agents (the native cannibals, the shipwrecked Spaniards, the English mutineers), agency acquires the further value of multi-agent (i.e. social) interaction: practices and then rules for coordination and constraint of the agents' degrees of freedom become essential, initially for the well-being of the agents constituting the MAS, and then for the well-being of the MAS itself. Note the shift in the level of abstraction: once the social space arises, we begin to consider the group as a group - e.g., as a community, or as a society - and the actions of the individual agents constituting it become elements that lead to the MAS' newly established degrees of freedom, or agency. The previous simple example may still help. Consider now a coffee machine and a timer: separately, they are two agents with different agency, but if they are properly joined and coordinated into a MAS, then the issuing agent has the new agency to make coffee at a set time. It is now the MAS that has a more complex capacity, and that may or may not work properly.

A social space is thus the totality of degrees of freedom of the agents one wishes to take into consideration. In history, such consideration - which is really just another level of abstraction - was largely determined by the territory and hence by a variety of forms of neighbourhood. In the example above, all the agents taken into consideration are chosen because of their relations to the same "Island of Despair". We saw that ICTs have changed all this. In hyperhistory, where to draw the line to 
include, or indeed exclude, the relevant agents whose degrees of freedom constitute the social space has become increasingly a matter of at least implicit choice, when not of explicit decision. The result is that the phenomenon of distributed morality, encompassing that of distributed responsibility, is becoming more and more common (Floridi forthcoming). In either case, history or hyperhistory, what counts as a social space may be a political move. Globalisation is a de-territorialisation in this political sense.

If we now turn to the political space in which the new MASs operate, it would be a mistake to consider it a separate space, over and above the social one: both are determined by the same totality of the agents' degrees of freedom. The political space emerges when the complexity of the social space-understood in terms of number and kinds of interactions and of agents involved, and of degree of dynamic reconfiguring of both agents and interactions - requires the prevention or resolution of potential divergences and the coordination or collaboration about potential convergences. Both are crucial. And in each case more information is required, in terms of representation and deliberation about a complex multitude of degrees of freedom. The result is that the social space becomes politicised through its informatization.

\subsection{Legitimacy}

It is when the agents in the social space agree to agree on how to deal with their divergences (conflicts) and convergences that the social space acquires the political dimension to which we are so used.

Two potential mistakes await us here. One, call it Hobbesian, is to consider politics merely as the prevention of war by other means. This is not the case, because even a complex society of angels (homo hominis agnus) would still require politics in order to further its harmony. Convergences too need politics. Out of metaphor, politics is not just about conflicts due to the agents' exercises of their degree of freedom when pursuing their goals. It is also, or at least it should be, above all, the furthering of coordination and collaboration by means other than coercion and violence. Second, and one may call this potential mistake Rousseauian, it may seem that the political space is then just that part of the social space organised by law. In this case, the mistake is subtler. We usually associate the political space with the rules or laws that regulate it but the latter are not constitutive, by themselves, of the political space. Compare two cases in which rules determine a game. In chess, the rules do not merely constrain the game, they are the game because they do not supervene on a previous activity: rather, they are the necessary and sufficient conditions that determine all and only the moves that can be legally made. In football, however, the rules are constraints because the agents enjoy a previous and basic degree of freedom, consisting in their capacity to kick a ball with the foot in order to score a goal, which the rules are supposed to regulate. Whereas it is physically possible, but makes no sense, to place two pawns on the same square of 
a chessboard, nothing impeded Maradona's 'hand of God' from scoring a goal, ${ }^{8}$ and that to be allowed by a referee who did not see the infringement.

Once we avoid the previous mistakes, it is easier to see that the political space is that area of the social space constrained by the agreement to agree on resolution of divergences and coordination of convergences. This leads to a further consideration, concerning the Transparent State.

\section{The Transparent State}

There are two senses in which the State can be transparent. Unsurprisingly, both come from ICTs and computer science, one more case in which the information revolution is changing our mental framework.

On the one hand, the State can be transparent in the sense that it moves from being a black box to being a white box. Citizens not only can see inputs and outputs, for example levels of tax revenue and public expenditure, they can also monitor how the State as a MAS works internally. This is not a novelty at all. It was a principle already popularised in the 19th century, when the State as we know it was in its infancy. However, it has become a renewed feature of contemporary politics due to the possibilities opened up by ICTs. This kind of transparency is also known as Open Government.

On the other hand, and this is the more innovative sense that I wish to stress in this contribution, the State can be transparent in the same sense in which a technology (e.g., an interface) is: invisible not because it is not there but because it delivers its services so efficiently, effectively, and reliably that its presence is imperceptible. When something works at its best, behind the scenes as it were, to make sure that we can operate as easily as possible, then we have a transparent system. This second sense of transparency should not be seen as a surreptitious way of introducing, with a different terminology, the concept of "Small State" or "Small Governance". On the contrary, in this second sense, the State is as transparent and as vital as the oxygen that we breathe. It strives to be the ideal butler. There is no standard terminology for this kind of transparent State that becomes perceivable only when it is absent. Perhaps one may speak of Gentle Government. It seems that the State can increasingly support the right sort of ethical infrastructure the more transparently (that is, openly and gently) it plays the negotiating game through which it takes care of the res publica.

\footnotetext{
${ }^{8}$ In Argentina v England (1986 FIFA World Cup), Maradona scored a goal by using his hand. "The ball went into the goal. Referee Ali Bin Nasser of Tunisia did not see the infringement and allowed the goal, much to the chagrin of the English players and management", http://en.wikipedia.org/ wiki/Argentina_v_England_(1986_FIFA_World_Cup)\#.22Hand_of_God.22_goal
} 


\section{Conclusion}

Six thousand years ago, a generation of humans witnessed the invention of writing and the emergence of the State. This is not accidental. Prehistoric societies are both ICT-less and stateless. The State is a typical historical phenomenon. It emerges when human groups stop living in small communities a hand-to-mouth existence and begin to live a mouth-to-hand one, in which large communities become political societies, with division of labour and specialised roles, organised under some form of government, which manages resources through the control of ICTs. From taxes to legislation, from the administration of justice to military force, from census to social infrastructure, the State is the ultimate information agent and so history is the age of the State.

Almost halfway between the beginning of history and now, Plato was still trying to make sense of both radical changes: the encoding of memories through written symbols and the symbiotic interactions between individual and polis-State. In 50 years, our grandchildren may look at us as the last of the historical, State-run generations, not so differently from the way we look at the Amazonian tribes, as the last of the prehistorical, stateless societies. It may take a long while before we shall come to understand in full such transformations, but it is time to start working on it. ${ }^{9}$

Open Access This chapter is distributed under the terms of the Creative Commons Attribution Noncommercial License, which permits any noncommercial use, distribution, and reproduction in any medium, provided the original author(s) and source are credited.

\section{References}

Floridi, Luciano. 2003. On the intrinsic value of information objects and the infosphere. Ethics and Information Technology 4 (4): 287-304.

Floridi, Luciano. 2007. A look into the future impact of ICT on our lives. The Information Society 23 (1): 59-64.

Floridi, Luciano. 2008. Artificial intelligence's new frontier: Artificial companions and the fourth revolution. Metaphilosophy 39 (4/5): 651-655.

Floridi, Luciano. 2010. Information - A very short introduction. Oxford: Oxford University Press.

Floridi, Luciano. 2011. The philosophy of information. Oxford: Oxford University Press.

Floridi, Luciano. forthcoming. The ethics of distributed morality. Science and Engineering Ethics 19 (3): 727-743.

Floridi, Luciano. forthcoming. The ethics of information. Oxford: Oxford University Press.

Floridi, Luciano, and Jeff W. Sanders. 2004. On the morality of artificial agents. Minds and Machines 14 (3): 349-379.

Floridi, Luciano, and Mariarosaria Taddeo. eds. forthcoming. The ethics of information warfare. New York: Springer.

\footnotetext{
${ }^{9}$ Many thanks to Massimo Durante, Charles Ess, and Ugo Pagallo for their many valuable comments on previous drafts of this chapter.
} 